African Research Review

An International Multidisciplinary Journal, Ethiopia

Vol. 8(3), Serial No. 34, July, 2014:78-91

ISSN 1994-9057 (Print) ISSN 2070--0083 (Online)

DOI: http://dx.doi.org/10.4314/afrrev.v8i3.6

\title{
The Key Factors for Effective Partnership Working in Community Capacity Building: Developing Country Context
}

\author{
Sanni, Ganiyu. A. O. \\ Doctoral Researcher \\ University of Wales in Association with the Greenwich School of \\ Management, London, 99 Poplar Place, Thamesmead North, Greenwich, \\ London, SE28 8BA \\ E-mail: s2agolatunji@yahoo.com \& ganiyu.sanni@gsm.org.uk \\ Tel: $+447529341869,+447535791870$
}

\begin{abstract}
The current socioeconomic conditions of many nations are challenging due to the global financial crisis and many institutions that facilitate Community Capacity Building-CCB are struggling to shoulder the expenses alone without being in some type of partnership with others. The concern is that organised partnership organizations with well-intentioned commitments sometimes produce unwelcome outcomes due to unnecessary dispute that mostly shorten the partnerships' life-span. Many studies have examined the key factors for effective partnership working, but did not identify the stages where each factor is paramount in partnership working. This paper intends to contribute to the development of theory on the key factors for effective partnership working in CCB from a developing country context. This paper adopted a single case study approach which is in line with the position of Stake (2005) and Yin (2003) on the possible rationales for using a single case study, and carried out interviews with 48 selected participants to gather informative data. This paper identified seven factors which were used to design a framework called 'Partnership Test Card-PTC' that might be used by existing partnership
\end{abstract}


organizations that involved in $C C B$ as check lists, and might serve as guides to organiser of partnership organization in developing countries.

Key words: AARSI partnership organization, effective partnership working, partnership framework, partnership test card, capacity building interventions

\section{Introduction}

The current socioeconomic conditions of many nations are challenging due to the global financial crisis and huge burden of debt for various nations to deal with. Many institutions that facilitate Community Capacity Building-CCB are struggling to shoulder the expenses alone without being in some type of partnership with others; although, the form of partnership varies between international bodies such as the United Nations (UN) and national governments, between national governments and private organizations, and between private organizations and non-governmental organizations (NGOs). Mitchell (2008, p.3) views partnership as

an agreement between two or more partners with a common interest in some outcome of the partnership, a common understanding of what is expected from each partner, and a belief that each partner will perform in accordance with the agreement that has been established.

Miller and Ahmad (2000, p.1) stressed that "partnerships between organizations, professions, and across sectors in the delivery of public services are now a major policy goal across both developed and developing world". The same view was echoed by Sullivan and Skelcher (2002) that partnership is the new language of public governance in the world. Liberato et al., (2011) pointed out that the important factors for achieving effective benefits in social and economic regeneration of any community are to understand its constituents, the ability to examine its capacity development and the ability to facilitate community engagement and partnership. Napier (2002) expressed CCB as a term used to describe the process by which the capability of the community is strengthened in order to play more active roles in the economic and social regeneration of their area through long-term ownership of the regeneration process. With the position of Napier (2002) on CCB, then there is need for effective partnership working among the relevant stakeholders within the community before the capability of the community can be strengthened to meet the regeneration of its area.

Edwards et al., (2000) stressed that partnership working has been recognised as the preferential means of management across a diverse raft of policy arenas including community development-CD. The authors stressed further that the recognition and growth of partnership deals were not only encouraged and supported by the politicians and public policy makers, but also by practitioners in economic and CD. 
The Key Factors for Effective Partnership Working in Community Capacity Building...

The concern is that organised partnership organizations with well-intentioned commitments sometimes produce unwelcome outcomes as a result of unnecessary dispute that mostly shorten the partnerships' life-span, although, it is not all partnership arrangements that usually materialized, survived and last forever due to inherent nature of change in human activities and social environments. Partnership dispute in CCB programmes/projects should be avoided because it can lead to unforgettable history in mind of the community's members expected to benefits from those programmes/projects.

However, some of these problems and its impacts can be minimized where there is effective framework in place that can serve as guides to anyone starting up partnership organization to facilitate $\mathrm{CCB}$, and also serve as check lists for existing partnership organizations that involved in CCB in order to monitor the effectiveness of partnership working. Many writers have tried to determine the key factors in partnership working and the reasons behind failure or success in many partnership deals. Kanter (1989) and Coulson (2005) pointed out that partnership working may fail for the following reasons: shifts in strategy by one or more partner; absence of a common framework; uneven levels of commitment; imbalances in power; imbalances in benefits; conflicting loyalties; and improper management. Edwards et al., (2000) noted that bureaucracy and control plays major constraints on partnership practice. Kuijpers and Meershoek (2013) in their study carried out in Kenya confirmed the previous mentioned factors by various writers such as trust, communication and power balances but from their own findings, they identified forming personal relations, continuous self-reflection and flexibility as key factors to the success of NGO-business partnership.

Major problem in the previous literature is that the key factors for effective partnership working were mentioned, but did not state the stages where each factor is paramount in partnership working. This similar concern was raised by Kuijpers and Meershoek that previous studies identified numerous factors to the success or failure in partnership deals, but the major questions are "which of these factors are critical and to what extent they are influenced by context" (Kuijpers and Meershoek, 2013, p.92). However, this paper intends to fill a gap by contributing to the development of theory on the key factors for effective partnership working in CCB from a developing country context by putting forward a framework that can capture the shortcomings on this subject area.

\section{Partnership concept}

Partnership is a versatile word that is hard to define (Lawless, 1991; Roberts et al, 1995). Sullivan and Skelcher (2002) stressed that the word 'Partnership' is used liberally in academic texts and policy documents and for this reason it has possessed 
a strong normative meaning especially in the contemporary governance environment. The authors presumed that the difficulty associated with the definition of partnership is related to the dynamic and fragmented nature of policy environment, although, the authors emphasised that those interpretations of partnership do not go beyond those policy areas. For example, the definition of partnership between voluntary sector and the State is viewed as "notions of dialogic and consensual decision-making and inclusive structures and processes" (Sullivan and Skelcher, 2002, p.5).

Many writers have defined partnership based on their understanding and for the context of their studies. In this paper, few definitions of partnership were mentioned in order to give insight about people understanding of the concept 'partnership'. Bailey et al., (1995, p.27) suggested that partnership "might be the mobilisation of a coalition of interests drawn from more than one sector in order to prepare and oversee an agreed strategy for the regeneration of a defined area", while Lorenz (1991, p.189) relates partnership with acceptable behaviour and trust by this definition "as a set of normative rules determining what behaviour is permissible and what constitutes a violation of trust". Newchurch (1999) views partnership from local government and community engagement context and then expressed it as a process by which local authority works together with partners in order to achieve better outcomes for the local community by appraising the needs of local stakeholders.

Edwards et al., (2000, p.2) defines partnership as "an arrangement which deliberately draws together the resources of specified partners in order to create a capacity to act with regard to a defined objective or set of objectives". This paper reckons with this definition and regards it as a comprehensive definition of partnership, because it includes four essential elements in partnership. First, in any partnership there must be agreed arrangement in place that stipulates the roles and status of each partner. Second, the specified partners mentioned in this definition are important element in partnerships, because the number and identity of partners involved must be known to all partners. Third, it allows pooling of resources together to enhance partnership capability, although, these resources may be in form of human, financial and material. However, these resources may be drawn from various industries or sectors of the economy; single sector (private sector only or public sector only), or mixed sectors (private and public sectors), single industry (e.g. from banking industry only) or different industries (e.g. from banking industry and manufacturing industry) of the economy. Fourth, the main motive of any partnership organization is to achieve desired outcomes that meet the interest of all partners involved.

Brinkerhoff (2002) defines partnership as "a dynamic relationship among diverse actors, based on mutually agreed objectives, pursued through a shared understanding of the most rational division of labour based on the respective comparative advantages of each partner". The author pointed out that the problem of focusing on 
ideal definitions of partnership is the ability to determine the degree to which the partnership can be functioned in reality.

Berry et al., (2011) pointed out that partnership approaches are largely set-up with the notion that no single agency can deal with complex community problems such as community safety and crime problems. However, this view has been voiced out before by Mackintosh (1992) when the author stressed that the aims of a partnership is to secure delivery of benefits which could not have been easily provided by any single agency acting alone. The benefits associated with partnership approaches to tackle complex socioeconomic problems facing communities cannot be underestimated and for this reason governments and communities at all levels are promoting partnership deals that could improve the well being of the people.

The importance roles of partnership working in facilitating CCB at all levels in developed countries such as United Kingdom (UK) and United States (US) cannot be ignored and it reflects in the figure stated by Sullivan and Skelcher (2002) that there are about 5,500 individual partnership bodies in the UK which are part of national initiative only, and this figure do not include those partnership bodies created by local councils and regional bodies to deal with communities' issues and to improve the well being of the people.

\section{The Key factors for effective partnership working}

Much of the literature reviewed identifies the key factors associated with effective partnership working, although, the most important factors for effective partnership working as mentioned in the previous studies are: established trust among the partners, balance of power among the partners, engaging the right people and formation of a committed team to steer the affairs of the partnership organization. The Scottish Executive (2002) noted that for partnerships to be successful the following factors have to be present; principle and purpose, resources and partnership, communication between partners, effective planning and understanding of specific objectives, and evaluation and monitoring. Edwards et al., (2000) pointed out from their empirical research study that the key issues that make partnership work are the followings: clarity of aims, right people, trust, good organization, and commitment to a way of working, adaptability, adequate resources and territorial competence.

In 1999, at the Asian Development Bank Institute conference on Public-Private Partnership-PPP in the Social Sector, it was highlighted that for PPP to be successful in the Social Sector then these key factors need to be considered; legal and regulatory framework, transparency and accountability, suitable public policies, commitment to public good, common understanding, sharing of resources, and consumers and community. Berry et al., (2011) in their empirical research study pointed out that 
mechanisms associated with better partnership working relies on leadership, data sharing and problem focus, communication and co-location, structures and experience. Fowler (2000) and Blagescu and Young (2005) emphasised that the success of any partnership organization depends on the degree to which ownership, power and commitment are shared among the partners involved. As stated earlier that it is not all partnership arrangements that will usually survived, because of inherent nature of change in human activities and social environments, however, some of these partnership arrangements can be maintained to last long in facilitating CCB programmes/projects if there is a proper framework in place and this paper intends to bridge gap on this subject area by contributing to the development of theory on the key factors for effective partnership working in CCB from a developing country context.

\section{Methodology}

This paper adopted a single case study and which is in line with the position of Stake (2005) and Yin (2003). These two authors are the recent advocates for the use of case study in social research. Stake (2005) emphasized that case study is the study of the particularity and complexity of a single case, coming to understand its activity within important circumstances (p. Xi) and which shared position with this paper. This paper also meets the five conditions laid down by Yin (2003) that a single case can be studied based on these five possible rationales: that it is a critical, extreme, typical, revelatory or longitudinal case (pp. 40-42). This paper studied Arrive Alive Road Safety Initiative-AARSI partnership organization in order to understand the uniqueness in its partnership operations for providing capacity building interventionsCBIs (road safety projects/programmes) to road safety problems in Nigeria by complementing the governments' efforts. There are many partnership organizations that focus on CCB programmes in Nigeria, but AARSI partnership organization was chosen for this paper, and its stakeholders who are willing to participate in research study were selected for interviews. The major reason for choosing AARSI partnership organization is because of its uniqueness (see diagram1 below for the AARSI partnership structure).

First, the AARSI organization has been in existence since May 2006 and it was launched by four Nigerian private organizations (Chevron Nigeria Plc, Diamond Bank Plc, First Bank Plc and Zenith Bank Plc) as a corporate social responsibilityCSR programme with the key stakeholders on road safety in Nigeria in order to complement governments' efforts on road safety through its CBIs to road safety problems on Nigerian roads. AARSI organization is currently based in Lagos State, but its mission is to spread its operations and apparatus across other States in Nigeria. Second, the sponsoring companies are from single sector (private sector), but from different industries (oil \& gas industry and banking industry) and AARSI's partners 
The Key Factors for Effective Partnership Working in Community Capacity Building...

are the relevant stakeholders on road safety. Third, each sponsoring company has their own established CSR Foundation that work with different NGOs of their choice to facilitate CCB in their host communities but, AARSI organization is allowed to function as an autonomous organization with a Board of Trustees that is made up of one representative each (with one alternate representative each) from the sponsoring companies. AARSI organization is an autonomous entity that identifies key stakeholders in the community and partners with them for the implementation of its programmes/projects without interference from the sponsoring companies, if it does not involve illegal activities.

This paper carried out pilot study with 25 participants through Skype and the outcomes from this exercise (including observations) were put on board for the fieldwork. The research fieldwork was carried out in Lagos State by conducting interviews with 48 out of 60 selected participants. This paper adopted purposive sampling by selecting a particular set of people that will provide relevant information and these samples is in line with Neuman's (2000) position that purposive sampling enables researchers to select very small samples that are particularly informative.

There are few questions designed for these exercises, but the two interview questions that are relevant to this paper are: what are the key factors for effective partnership working in AARSI partnership organization and in your view, what are the strengths and weaknesses in AARSI partnership working? The data collected were analysed by data display and analysis method based on Miles and Huberman (1994), in which data were placed into different order then followed by constructing a matrix of categorizations, while the relevant data were fixed under their categories. This paper identified seven themes; trust among the partners, common understanding, legal framework, committed team, appropriate resources, accountability and achievement. These themes were then used to design a framework called 'Partnership Test Card-PTC' (see Table1 below) which might be used as a benchmark to examine the effectiveness of partnership working because of the key factors highlighted as criterion and indicators, and also it displays the stages at which each factor is paramount to partnership working. The PTC might be used by existing partnership organizations that involved in CCB as check lists to monitor partnership working, and also serve as guides to anyone starting up partnership organization in facilitating $\mathrm{CCB}$ especially in developing countries.

\section{Partnership test card-PTC}

This paper explained the PTC extensively in order to provide understanding on this framework. Since the partnership organizations' approach can be influenced by the regulations or by their sector's practices so this framework will be suitable to partnership organizations that centred on CCB. This paper identified the key factors 
associated with partnership working in promoting CCB based on derived knowledge from the previous studies, the outcomes of the interviews conducted for this study, and understanding of the researcher in relation to partnership working from a developing country context. The PTC framework is explained below:

Trust among the partners- trust is the foundation of any form of relationships. All organizations that intends to participate in partnership arrangement must developed trust first and all partners involved need to trust each other or one another. Once there is established trust among the partners, it essential to maintain the trust because if that trust is lost the partnership relationship will collapse. Trust in partnership arrangement in promoting CCB needs to be developed over long period of time to avoid partnership dispute that can be termed as mistrust, which can lead to unforgettable history in mind of the community's members expected to benefits from those CCB programmes/projects. Many writers such as Milbourne et al., (2003), Brady (2013) and Kuijpers and Meershoek (2013) have pointed out trust as a key factor in partnership working.

Common understanding- for partnership organizations to maintain their trust and relationship in partnership arrangement especially in promoting CCB then the following issues (clear objectives, clear responsibility of each partner, clear identity of each partner and defining expected outcomes) must be thoroughly fine-tune and cleared to all partners before the commencement of business. All the partners involved must agree to the stated objectives and must also agree to individual responsibility. If there is need to adjust the partnership's stated objectives or responsibility of any partner then it must be done with mutual agreement, because if not the weaker partners can feel oppressed. The identity of each partner must be known to all partners involved to promote trust and to deal with individual differences at early stage. The expected outcomes of the partnership arrangement must be known to all partners to avoid dispute over achievement.

Legal framework- legal framework is an essential factor that enhances partnership working among partners. The partnership arrangement should be put in writing and must be known by all partners involved (memorandum of understanding). The legal framework will help the partnership organization to stop unruly behaviours among the partners. It will help to reduce partnership dispute that can arise if one of the existing partners intend to recommend new partner to join them or if one the existing partners is willing to exit from the partnership organization. Legal framework is also useful in conflict-resolution in order to provide peaceful resolution process.

Committed team- for partnership organization to succeed in their operations and to meet their stated objectives then there is need for proper arrangement for its management. The management group (committed team) of the partnership need to be 
The Key Factors for Effective Partnership Working in Community Capacity Building...

formally established and recognised by all parties involved. There is need for adequate commitment from each partner organization and their respective representatives in order to allow for integration and proper flow of ideas that will be of benefit to the partnership organization. McInnes (2007) argued that leadership and management style are two special identities that must be recognised by partnership organization in order to overcome other challenges associated with partnership. Berry et al., (2011) pointed out the importance of dedicated programme coordinator with independent authority to take decision while Brady (2013) recognised the roles of leadership and communication in partnership success.

Appropriate resources- this factor is essential to partnership working and to the success of partnership organizations. The partnership organizations can easily strive to meet their stated objectives if it has appropriate resources in place with greater commitment from all parties involved. All these resources (human resources, financial resources, logistic support when/where it is necessary and partnership networking) need to be available because it is associated with the partnership organizational capability and competency.

Accountability- when there is transparency through accountability it helps to enhance trust and commitment among the parties involved. There should be proper documentation of partnership activities and transactions, and which must be available to all parties involved at appropriate time or agreed time.

Achievement- certain partners consider achievement as a test tool that helps to determine if there is need for more commitment or there is need to opt out of the partnership arrangement. Partnership organizations use different variables and parameters to determine their achievements. The achievement of partnership organization in regards to meeting its stated objectives can be determined by assessing its activities and its impact. The other issues that can be considered are by assessing if there is improvement in organizational capability and partnership sustainability of the partnership organization.

Apart from the trust among the partners that must reflect at all times and at all levels of partnership arrangement, column 1 to 4 (common understanding, legal framework, committed team, appropriate resources) should be an area of interests to anyone starting up partnership organization, but the existing partnership organizations need to reflect on all the columns (column 1 to 6 ), while column 4 to 6 (accountability and achievement) can also be used to examine the internal and external outcomes of partnership working by the existing partnership organizations.

Clarifications on these columns, column 1 to 4 do not serve the same purpose for the existing partnership organizations and the organizer of new partnership organization towards CCB. For the organizer, column 1 to 4 serves as guides that states the 
expected elements required for partnership organization to succeed and these elements must be in place before the commencement of operations. For the existing partnership organizations, column 1 to 4 serves as check lists to examine if these expected elements are in place during the course of their operations and if there is need for mutual adjustment. In addition, for the existing partnership organizations, column 4 provides the indicators to be used in evaluating and monitoring the internal outcomes of partnership working (especially the organizational capability) in order to determine if these resources have improved during the course of operations.

Column 5 serves as sources of information for the existing partnership organizations in assessing the internal and external outcomes of partnership working, but the information in column 5 should be corresponded with the column 4 in assessing the overall internal outcomes of partnership working. The achievements of partnership working in term of improved organizational capability and improved relationship among the partners (partnership sustainability) are the overall internal outcomes as appeared in column 6 while the achievements in term of meeting stated objectives of the partnership organization are the overall external outcomes as appeared in column 6.

This paper posits that assessors/evaluators should determine the achievements of partnership organization in meeting their stated objectives (external outcomes) based on their implemented programmes/projects and their impacts on the expected beneficiaries, however, appropriate indicators should be selected in line with the available information in column 5. In addition, the assessors/evaluators can also add primary data collected separately to the available information in column 5 when examining the overall external outcomes. This paper maintains that assessors/evaluators can use any research approach to examine the outcomes (both internal and external outcomes) of the partnership working.

\section{Conclusions}

This paper intends to fill a gap by contributing to the development of theory on the key factors for effective partnership working in CCB from a developing country context by putting forward a framework called Partnership Test Card. This paper maintains that the PTC framework will be an importance tool to any one starting up partnership organization to facilitate $\mathrm{CCB}$, because it serves as guides that can avert future disputes among partners and which might help the partnership organization to stay healthy for long or forever. 


\section{AARSI Partnership Organisation}

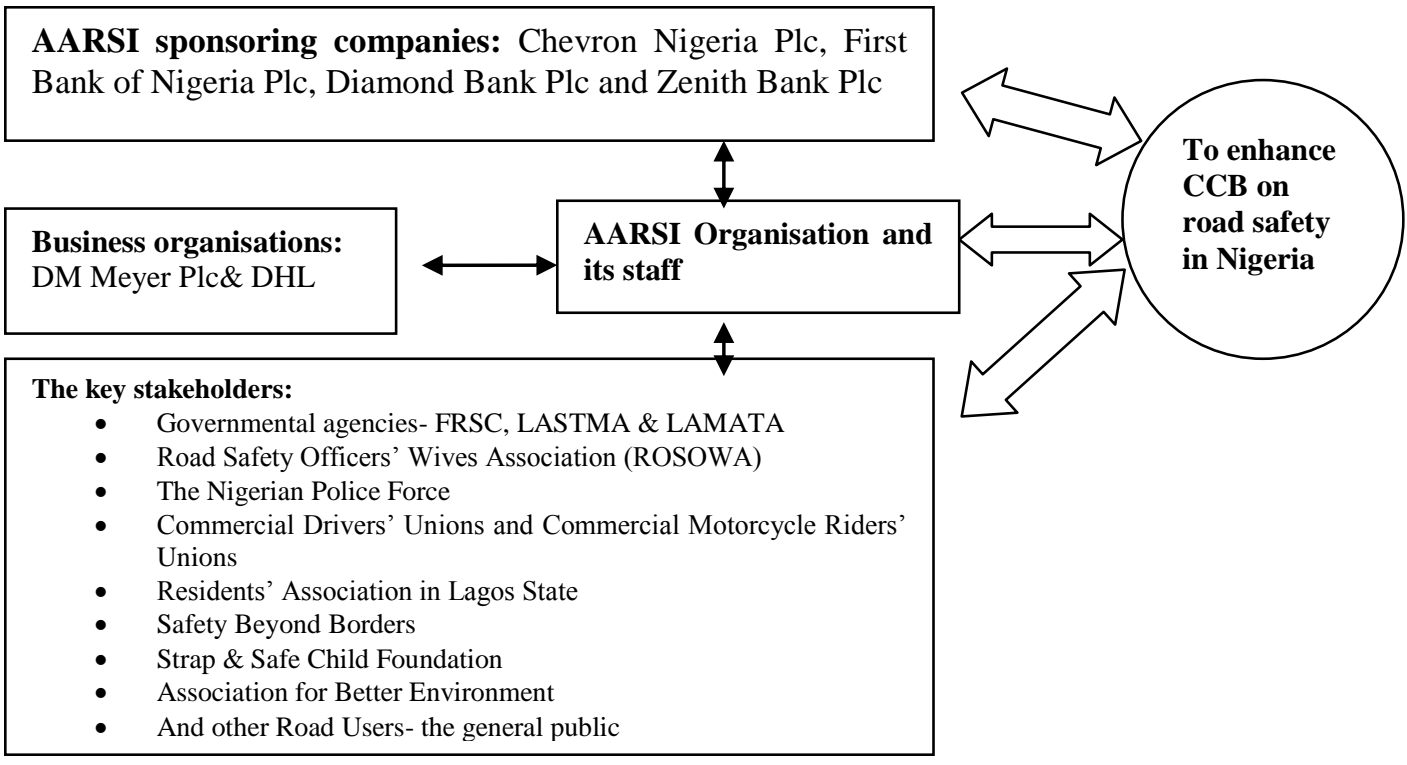

Diagram1-Source: Author 


\begin{tabular}{|c|c|c|c|c|c|}
\hline \multicolumn{6}{|c|}{ Trust among the partners } \\
\hline $\begin{array}{l}\text { Common } \\
\text { understanding (1) }\end{array}$ & Legal framework (2) & Committed team (3) & $\begin{array}{l}\text { Appropriate } \\
\text { resources (4) }\end{array}$ & Accountability (5) & Achievement (6) \\
\hline $\begin{array}{l}\text { Clear responsibility } \\
\text { of each partner } \\
\text { Clear identity of } \\
\text { each partner }\end{array}$ & $\begin{array}{l}\text { Agreement to undertake } \\
\text { activities jointly } \\
\text { Agreement to constitute } \\
\text { formal governing body } \\
\text { Agreement on the } \\
\text { organizational structure } \\
\text { Agreement to comply with } \\
\text { governmental legislations } \\
\text { associated with the } \\
\text { partnership activities } \\
\text { Agreement on entry process } \\
\text { for new partner and exit } \\
\text { process for existing partners } \\
\text { Conflict-resolution } \\
\text { mechanism in place }\end{array}$ & $\begin{array}{l}\text { Sense of ownership by all partners' } \\
\text { representatives } \\
\text { Full-time programme coordinator to } \\
\text { oversee day-to-day activities of the } \\
\text { partnership organization } \\
\text { Leadership quality expected from the } \\
\text { team members } \\
\text { Mutual respect for all team members } \\
\text { Effective communication flow among } \\
\text { the team members } \\
\text { Regular face to face meeting including } \\
\text { scheduled meeting } \\
\text { Team members have experienced in } \\
\text { team work and partnership deal } \\
\text { Motivate with common vision }\end{array}$ & $\begin{array}{l}\text { Human resources } \\
\text { Financial } \\
\text { resources } \\
\text { Logistic support } \\
\text { when/where it is } \\
\text { necessary } \\
\text { Partnership } \\
\text { networking }\end{array}$ & $\begin{array}{l}\begin{array}{l}\text { Documentation of } \\
\text { contracts } \\
\text { transactions }\end{array} \\
\text { and } \\
\begin{array}{l}\text { Documentation of } \\
\text { necessary reports and } \\
\text { partnership activities }\end{array} \\
\text { Annual report }\end{array}$ & $\begin{array}{l}\text { Meet stated objectives } \\
\text { of the partnership } \\
\text { organization } \\
\text { Improved } \\
\text { organizational } \\
\text { capacity } \\
\text { Improved relationship } \\
\text { among the partners } \\
\text { (partnership } \\
\text { sustainability) }\end{array}$ \\
\hline
\end{tabular}

Table1-Source: Author (Partnership Test Card-PTC) 
The Key Factors for Effective Partnership Working in Community Capacity Building...

\section{References}

Bailey, N., Baker, A., \& MacDonald, K. (1995). Partnership Agencies in British Urban Policy. London: UCL Press

Berry, G., Briggs, P., Erol, R., \& van Staden, L. (2011). The effectiveness of partnership working in a crime and disorder context- a rapid evidence assessment. Research Report 52, ISSN 1756-3666

Blagescu, M., \& Young, J. (2005). Partnerships and Accountability: Current thinking and approaches among agencies supporting Civil Society Organisations. Overseas Development Institute, London, Working paper No 255

Brady, M. (2013). The nature of health and social care partnership. Nursing Management, 19(9), pp. 30-35

Brinkerhoff, J.M. (2002). 'Assessing and improving partnership relationships and outcomes: A proposed framework'. Evaluation and Program Planning, 25, pp.215-231

Coulson, A. (2005). 'A plague on all your partnerships: theory and practice in regeneration'. International Journal of Public Sector Management, 18(2), pp.151-163

Edwards, B., Goodwin, M., Pemberton, S., \& Woods, M. (2000). Partnership Working in Rural Regeneration. Findings 039, Bristol: Joseph Rowntree Foundation

Fowler, A. (2000). Questioning Partnership: The Reality of NGO Relations in the Aid System. Institute of Development Studies, 31(3), IDS Bulletin: University of Sussex

Kanter, R.M. (1989). When Giants Learn to Dance. New York: Simon \& Schuster

Kuijpers, L.M.F., \& Meershoek, A.M. (2013). NGO-Business Collaboration in Kenya: A Case Study and broader Stakeholder Analysis. Journal of Corporate Citizenship, 50, pp. 91-105

Lawless, P. (1991). Public-Private Sector Partnerships in the United Kingdom. Centre for Regional, Economic and Social Research, Working Paper 16, Sheffield: Sheffield City Polytechnic

Liberato, S.C., Brimblecombe, J., Ritchie, J., Ferguson, M., \& Coveney, J. (2011). 'Measuring capacity building in communities: a review of the literature'. BMC Public Health, 11, pp.1-10

Lorenz, E.H. (1991). Community Against Government- The British Community Development Projects 1968-78. London: Heinemann

Mackintosh, M. (1992). 'Partnerships: Issues of Policy and Negotiation'. Local Economy, 7(3), pp.210-24 
McInnes, K. (2007). A Practitioner's Guide to Interagency Working in Children's Centres: A Review of Literature. Barnardo's Policy and Research Unit, Ilford

Milbourne, L., Macrae, S., \& Maguire, M. (2003). Collaborative solutions or new policy problems: Exploring multiagency partnerships in education and health work. Journal of Educational Policy, 18(1), pp.19-35

Miles, M.B., \& Huberman, A.M. (1994). Qualitative Data Analysis (2 ${ }^{\text {nd }}$ edition). Thousand Oaks: Sage

Miller, C., \& Ahmad, Y. (2000). Collaboration and Partnership: An Effective Response to Complexity and Fragmentation or Solution Built on Sand. International Journal of Sociology and Social Policy, 20(5), pp.1-38

Mitchell, M. (2008). 'An Overview of Public Private Partnerships in Health', Publication from International Health Systems Program, Department of Global Health and Population, Harvard School of Public Health

Napier, A. (2002). 'Lessons for community capacity building: a summary of the research evidence'. Mount Isa Centre for Rural and Remote Health (MICRRH)

Neuman, W.L. (2000). Social Research Methods ( $2^{\text {nd }}$ edition). London: Allyn and Bacon.

Newchurch (1999). Local Authority Partnerships: A Review of the Literature, Newchurch/DETR Partnership Series Paper 2, London: DETR

Roberts, V., Russells, H., Harding, A., \& Parkinson, M. (1995). Public, Private, Voluntary Partnerships in Local Government. Luton: Local Government Management Board

Scottish Executive (2002). Partnership Working: Key Issues Around Evaluation. Office of the Chief Researcher, July (2002) Edinburgh: Scottish Executive Social Research

Stake, R. (2005). The art of case study research. Thousand Oaks, CA: Sage

Sullivan, H., \& Skelcher, C. (2002). Working Across Boundaries: Collaboration in Public Services. Hampshire: Palgrave Macmillan

The Asian Development Bank Institute (1999). 'What is needed for successful Public Private Partnerships in the Social Sector?' responses from the Asian Development Bank Institute conference on Public-Private Partnerships in the Social Sector, July, Tokyo-Japan

Yin, R. K. (2003). Case Study Research: Design and Method (3rd edition). London: Sage 